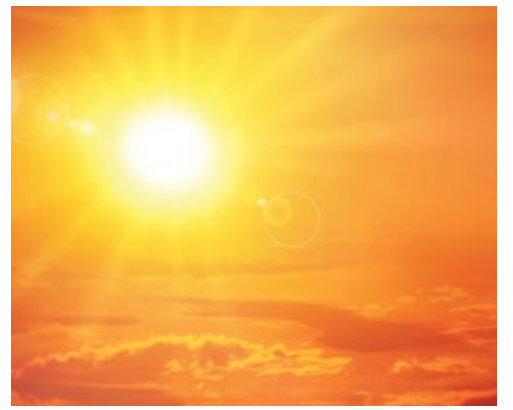

CPD

Peter W Tait, Sujata Allan,

Anthea L Katelaris

\section{Background \\ The burden of heat-related morbidity and mortality will increase as heatwaves become more frequent and intense as a result of global warming and climate disruption. The elderly and those with chronic disease are worst affected. Most heat-vulnerable people are managed in general practice, and so general practitioners (GPs) need to begin planning for how to prevent and manage heat-related morbidity and mortality.}

\section{Objective \\ The aim of this article is to introduce GPs to heat-related morbidity and mortality, present a model to help guide thinking about prevention of heat-related disease, and provide examples of actions that practices and practitioners can take.}

\section{Discussion}

GPs need to be aware of heat stress as a potential cause of morbidity and mortality. Their role crosses the three preventive levels: 1) advocating for mitigating greenhouse gas emissions (primordial); 2) identifying vulnerable people in their practices; and 3) working with these patients and their relatives to incorporate primary and secondary prevention strategies in care planning.

\title{
Preventing heat-related disease in general practice
}

CASE

Mrs Krisolakis, aged 78 years, is a widow and long-time patient at your practice who has been admitted to the local hospital. This followed four very hot days and three consecutive nights where the temperature did not fall below $29^{\circ} \mathrm{C}$. This morning her daughter, Helen Mitchell, comes to see you. Helen asks, 'My mother is in hospital with heat stroke and heart failure; what can you do to stop this happening again?' For the patient's further history refer to Box 1, and for medications refer to Box 2 .

To respond to Helen's question, we need to understand the broader context and range of heat-related illness, the role and foci for intervention as general practitioners (GPs), the action we can take and the resources available to guide us.

\section{Context}

Anthropogenic global warming (AGW) and consequent climate disruption are established and irrevocable but mitigatable consequences of human greenhouse gas (GHG) emissions, which are forecast to have a wide range of health outcomes. ${ }^{1}$ It is important to realise that AGW is one part of a much larger set of ecosystem changes that are synergistically affecting human civilisation. ${ }^{2}$ Any action to prevent the health and wellbeing consequences of AGW occurs within this context.

The broad health effects of AGW were well described in a recent edition of this journal. ${ }^{3}$ This present article will focus on preventing the direct effects of heat.
Extreme heat-related morbidity and mortality already occur. Heatwaves are already becoming hotter, longer and more frequent. ${ }^{4}$ The intensity, duration and frequency of heatwaves will increase during the 21 st century because of AGW, and so health outcomes will also increase. Modelling shows that under the most extreme GHG emission scenario, in the period 2031-80 there will be an estimated $471 \%$ increase in heatwave-related mortality across three Australian cities (Brisbane, Sydney and Melbourne), compared with the period 1971-2010. ${ }^{5}$ GPs have a key part to play in reducing the burden of heatwaves on people and populations. However, the specifics of what that part entails have not been explored in detail.

While there is no standard definition of heatwaves, a generally accepted definition is three or more days of high maximum and/or minimum temperatures that are unusual for a given location. ${ }^{6}$ The frequency and intensity of heatwaves has already increased in Australia, and this trend will continue. ${ }^{7}$

Over the past 100 years, extreme heat events are estimated to have caused more deaths than all other natural hazards combined. ${ }^{8}$ Furthermore, deaths associated with extreme heat are underestimated, as only a small proportion, such as from heat stroke, are directly attributable to heat. The majority of heat-related morbidity and mortality are due to 
exacerbation of underlying medical conditions, particularly cardiovascular, pulmonary and renal disease, and so are not captured by death registration data. While heat-associated deaths do occur outside designated heatwave periods, the health consequences of heatwaves exceed the effects of isolated hot days. ${ }^{9}$

The morbidity and mortality due to heatwaves create considerable burden and have an impact on health services. The 2009 Victorian heatwave resulted in a $62 \%$ increase in all-cause mortality, compared with the same period over the previous five years. ${ }^{10}$ Ambulance emergency caseload increased by $25 \%$, and a home-visit GP service had a four-fold increase in call-outs for heat-related conditions and double the calls to attend deceased persons. A modelling study found that in NSW, very intense heatwaves were associated with a $>10 \%$ increase in both mortality and ambulance call-outs and a 3.8\% increase in emergency department presentations across the state. ${ }^{11}$ A 2004 heatwave in Brisbane was associated with a $23 \%$ increase in non-external mortality (ie deaths from all causes except injury and suicide) and a $20 \%$ increase in cardiovascular mortality, compared with the same period in previous years. ${ }^{12}$

The burden of excess morbidity and mortality is carried proportionally more by vulnerable populations, including children, older people, people who are experiencing homelessness and those who are socially isolated. ${ }^{9}$ This is due to a decreased capacity for physiological and behavioural adaptation, combined with poorer underlying health. GPs are generally already involved with these groups.

\section{Heat-related disease}

A range of diseases directly related to heat can occur, from minor heat effects, such as heat rash, cramps, fatigue, dizziness and syncope, to heat exhaustion, heat injury and heat stroke. Normal hot weather can cause all of these, but heat exhaustion, injury and stroke are more likely during heatwaves. Occupational or recreational physical activity in the heat makes heat stress more likely.

This article does not describe the basic physiology of thermoregulation and thermal comfort, which is well covered elsewhere. ${ }^{13}$

\section{Role and focus of general practice}

It is always better to prevent disease and the complications of disease. We frame this article using the recognised four levels of prevention: primordial, primary, secondary and tertiary (although tertiary is not applicable for heat stress pre-hospital). ${ }^{14}$

A second element to prevention is recognising the GP's responsibility for action. Figure 1 maps the pathways to heat morbidity and mortality. The framework shows that there are individual-level

\section{Box 1. Further history - Mrs Krisolakis}

- Lives on the fourth floor of an apartment complex in Western Sydney

- Past history:

- no surgery

- hypertension since 1995

- myocardial infarction with two coronary artery bypass grafts in 2001

- some cardiac failure since 2013

- one admission for stabilisation of congestive cardiac failure in 2014

- stress and urge urinary incontinence

- stage 3b chronic kidney disease.

- Most recent blood pressure 145/88 $\mathrm{mmHg}$

- Body mass index $33 \mathrm{~kg} / \mathrm{m}^{2}$

- Estimated glomerular filtration rate $36 \mathrm{~mL} /$ minute $/ 1.73 \mathrm{~m}^{2}$ (normal: $>90 \mathrm{~mL}$ / minute/1.73 $\mathrm{m}^{2}$ )

- Most recent full blood count and liver function tests were unremarkable

and societal-level responsibilities, and these operate in personal acclimatisation and behavioural and technological domains. It recognises both behavioural and technological aspects to prevention, which need inclusion in any heat disease prevention plan. In general practice, it helps to focus attention on whether the GP needs to work with the patient (personal level), with community groups (personal and societal level) or as an advocate to governments for change at a societal level on preventive action.

\section{Preventive actions}

Table 1 summarises preventive actions for heat effects.

\section{Primordial prevention}

There are strong links between heat, carbon emissions and air pollution. Primordial prevention in this technological domain is a societal-level advocacy activity. As doctors, we carry a responsibility to safeguard our patients' health and wellbeing by advocating through our colleges and professional bodies to government and industry for a coherent Australian strategy to reduce GHG emissions. Not only will action to reduce GHGs mitigate future warming, but there are more immediate health benefits across several domains, particularly improved air quality. The proposed National Strategy for Climate, Health and Wellbeing, led by the Climate and Health Alliance, is one example of health organisations joining together to advocate for a beneficial action. ${ }^{15}$

Heat and air pollution interact in two ways to harm health. First, heatwaves increase ground-level ozone, the main component of photochemical smog, created when oxides of nitrogen $\left(\mathrm{NO}_{\mathrm{x}}\right)$ and

\section{Box 2. Medications - Mrs Krisolakis}

Ramipril 10 mg morning

Atenolol 100 mg morning

Furosemide $20 \mathrm{mg}$ morning

Spironolactone $25 \mathrm{mg}$ morning

Oxybutynin $3.9 \mathrm{mg} / 24$ hour patch 3-4th daily

Paracetamol as required 
volatile organic compounds (VOC) react in the presence of sunlight. Major sources of $\mathrm{NO}_{\mathrm{x}}$ and VOC include motor vehicle exhaust, industrial processes and coalfired power stations. ${ }^{16}$ Ground-level ozone causes lung inflammation and respiratory symptoms, even with healthy lungs, and is worse in the presence of asthma or lung disease. ${ }^{17}$ Ozone national air quality standards are most commonly exceeded in summer months during heatwaves; for example, in January 2017, dangerous levels of ozone prompted NSW Health to issue a warning to those with asthma and respiratory conditions. ${ }^{18}$

Secondly, air pollution from electricity generation, transport and other sources directly affects health. Particulate matter (PM2.5 and PM10) is classified as a class 1 carcinogen ${ }^{19}$ along with tobacco and asbestos. Particulate matter, sulphur dioxide $\left(\mathrm{SO}_{2}\right)$ and $\mathrm{NO}_{\mathrm{x}}$ contribute to ischaemic heart disease and lung disease. ${ }^{20}$ In the Sydney Greater Metropolitan Region, distant coal-fired power stations (in the Hunter Valley, Central Coast and Lithgow) up to $140 \mathrm{~km}$ away ${ }^{21}$ are a significant source of $\mathrm{SO}_{2}$ and $\mathrm{NO}_{\mathrm{x}} \cdot{ }^{16}$ Reducing this air pollution has measurable health benefits. ${ }^{22}$ Therefore, measures to reduce carbon emissions, one of the major drivers of AGW, have direct co-benefits for health by reducing air pollution.

Mrs Krisolakis lives in Western Sydney, an area particularly prone to the urban heat island (UHI) effect. The UHI effect describes localised warming in urban areas due to large areas of paved and darkcoloured surfaces, which absorb rather than reflect solar energy. This exacerbates heatwaves. Additional heat generated by human activity, such as vehicle engines and air conditioning, adds to this effect. ${ }^{23}$ During summer, temperatures in treeless urban areas are, on average, $12.8^{\circ} \mathrm{C}$ hotter than vegetated non-urban areas. ${ }^{24}$

In Mrs Krisolakis's area, the Western Sydney Regional Organisation of Councils has worked with the Local Health District to develop a project to tackle UHI. ${ }^{24}$ Such action also has health co-benefits; improving tree cover and green spaces reduces the $\mathrm{UHI}^{24}$ and additionally provides more liveable spaces that promote physical activity. ${ }^{25}$ Access to green space also benefits problem childhood behaviour, stress, anxiety and depression. ${ }^{23}$

In addition to urban design, designing housing to minimise accumulation of heat is a further focus for preventing

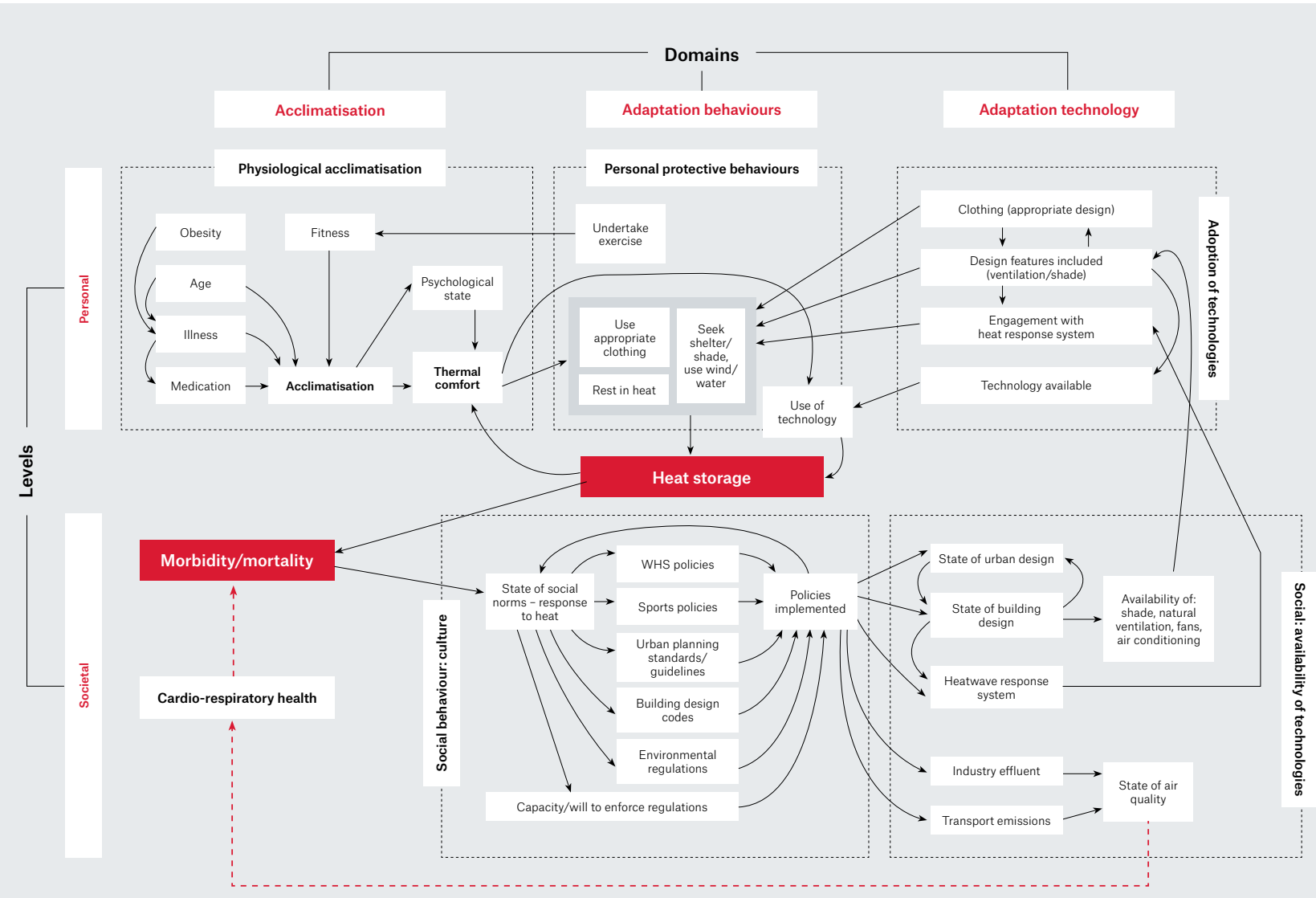

Figure 1. This influence system diagram illustrates the major elements for consideration in mapping loci for preventive action for heat stress (adapted from Tait PW, Hanna EG). ${ }^{28}$ There are two levels of action across three domains for action. Within each cell are examples of the elements that need to be accounted for in planning prevention.

WHS, workplace health and safety 
heat-related disease. This may involve retrofitting existing housing stock. All these measures would be detailed in a National Strategy for Climate, Health and Wellbeing. ${ }^{15}$

Encouraging physical activity is central for promoting health and wellbeing and managing chronic diseases. Exercise is also important for acclimatisation to heat. However, experience shows it is the behaviour least likely to be taken up by patients, so its use as a prevention activity is limited.

\section{Primary prevention}

Mrs Krisolakis is elderly, has chronic disease, lives alone in a low socioeconomic area and is at high risk of harm from extreme heat. It is therefore important to engage in primary prevention.

All states and the ACT, and some local governments, have heatwave-response plans (Box 3) that provide information for health professionals and the public. How general practices are alerted to impending heatwaves and integrated into response plans needs further exploration. The GP's

\section{Table 1. Heat stress prevention}

\begin{tabular}{lll}
\hline Level & Objective & Action \\
\hline Primordial & $\begin{array}{l}\text { Personal } \\
\text { Improve acclimatisation }\end{array}$ & $\begin{array}{l}\text { Address risk factors - particularly } \\
\text { exercise and improved fitness }\end{array}$ \\
& $\begin{array}{l}\text { Improve understanding among } \\
\text { patients and family }\end{array}$ & Provide information and education \\
\hline $\begin{array}{l}\text { Societal } \\
\text { Mitigate greenhouse gas emissions } \\
\text { and improve air quality }\end{array}$ & $\begin{array}{l}\text { Advocate for National Strategy } \\
\text { for Climate, Health and Wellbeing }\end{array}$ \\
& $\begin{array}{l}\text { Pre-emptive adaptations } \\
\text { Advocate to local and state/territory } \\
\text { governments for good urban planning } \\
\text { (parks and gardens) and heat-adaptive } \\
\text { building design, including pale roofs }\end{array}$ \\
\hline
\end{tabular}

\begin{tabular}{ll}
\hline Primary & Personal/practice \\
& Reduce exposure to heat
\end{tabular}

Education and information Personal plans for heat events included in health checks and care plans

Minimise factors affecting response to heat

Shelter, clothing, protective behaviours Practice registers of vulnerable patients

Pre-heatwave review/assessment procedures

Medication review and dose

adjustment if needed

Societal

Regional and local preparedness

Personal

Reduce effects of heat

$\begin{array}{ll}\text { Secondary } & \text { Personal } \\ & \text { Reduce effects of heat }\end{array}$

Heatwave warning systems and localised response plans

Seek shelter

Ensure hydration

Check and assess

Evacuation if needed role here is translating the societal-level heat-response plans into individualised plans for patients, and working with patients and their relatives on actual implementation steps.

Education forms a cornerstone of primary prevention for patients such as Mrs Krisolakis - for example, by providing information on how to avoid or minimise her heat exposure by:

- maintaining hydration

- avoiding unnecessary physical activity

- avoiding going outside during the hottest part of the day

- wearing light-coloured, loose-fitting cool clothing

- using light-coloured curtains or shade windows

- closing internal doors

- moving to the eastern side of the house in the afternoon

- using air conditioning and/or fans (refer below) if available - including going to air-conditioned public places such as shopping centres and public libraries

- having battery-operated equipment such as radios (with spare batteries) and charged mobile phones in case of a power outage, which is more common in heatwaves as energy demand peaks

- stocking up on food that does not require cooking

- having a backup plan if reliant on electricity for medical equipment.

Given that Mrs Krisolakis is elderly, the usefulness of fans is not clear, as there is concern they may increase dry heat gain and dehydration. However, in non-extreme heat and provided adequate hydration, fans can be useful in assisting cooling. ${ }^{26}$

On a practice level, assessment of heat vulnerability can be brought into health assessments and care planning. Factors to consider include disease profile, medications that interfere with thermoregulation or response to heat, ${ }^{27}$ links to community resources, and a heatresponse plan incorporating the factors listed previously. Including a heatwave action plan into care plan templates may prompt this step. Practices could keep a register of their most vulnerable patients and establish protocols for checking on them by phone call, clinic review or home visit during a heatwave. 


\section{Box 3. Resources}

State and territory heat-response plans

\section{Queensland}

- Heat Wave Response Plan, www.health.qld.gov.au/_data/assets/pdf_file/0032/628268/ heatwave-response-plan.pdf

New South Wales

- Beat the heat - Information for health professionals, www.health.nsw.gov.au/environment/ beattheheat/Pages/information-for-health-professionals.aspx

Australian Capital Territory

- Avoiding heat-related stress, www.health.act.gov.au/about-our-health-system/populationhealth/fact-sheets

Victoria

- Extreme heat and heatwaves, www2.health.vic.gov.au/public-health/environmental-health/ climate-weather-and-public-health/heatwaves-and-extreme-heat

Tasmania

- Heatwave ready Tasmania, www.dhhs.tas.gov.au/_data/assets/pdf_file/0005/236525/ Heatwave_Ready_Tasmania_Nov_2016.pdf

South Australia

- SA Health Extreme Heat Strategy, www.sahealth.sa.gov.au/wps/wcm/ connect/Public+Content/SA+Health+Internet/Protecting+public+health/ Emergency+management/Extreme+heat

Western Australia

- General advice, ww2.health.wa.gov.au/Articles/F_l/Heatwave

- Health advice, http://healthywa.wa.gov.au/Articles/F_l/Heat

Climate forecasts

- Overall climate information, www.climatechangeinaustralia.gov.au/en

- Regional projections for an indication of what is likely in your area, www.climatechangeinaustralia.gov.au/en/climate-projections/future-climate/regionalclimate-change-explorer/super-clusters

Where risky medications are identified, these may need dose adjustments during a heatwave. Systems to review vulnerable patients when a heatwave is forecast will be necessary.

Finally, for other vulnerable groups, particularly children and people exposed occupationally and recreationally, the GP's role extends to alerting people to their risks and providing advice or a source of advice for the patients. In Australia, amateur and professional sportspeople of all ages need to be aware of hot weather forecasts when planning events. If the GP is a team doctor, first aider, coach or parent, they have a responsibility to advocate for sporting and occupational events to be postponed or modified (societal and personal behaviour change). For minor heat effects, personal advice and public education campaigns about simple behaviour changes, appropriate clothing, activity levels and hydration would be sufficient.

\section{Secondary prevention}

The focus of secondary prevention is to minimise the effects of heat once they manifest. Essentially, this is building advice about recognising the onset of heat effects at the personal level (Box 4) into the plan and specifying what action to then take. The onus would be on Mrs Krisolakis to recognise these effects and act, and on Helen to regularly phone her mother to check how she is. Once heat stress has begun, the best action is urgent assessment and rescue to a safer, cooler place while ensuring hydration is maintained.

It is important to remember that most heat mortality and morbidity is from decompensation of existing disease because of increased physiological stress in heatwave conditions. Proactive management of exacerbation of chronic conditions, particularly cardiac and renal diseases, is therefore essential.

\section{Box 4. Heat stress symptoms}

Headaches

High temperature

Profuse sweating

Cold, clammy pale skin

Fatigue, weakness and restlessness

Nausea and vomiting

Weak but rapid pulse

Poor coordination

For those vulnerable people who do not have support similar to Mrs Krisolakis's, instituting community visiting for assessment during heatwaves would be crucial. Where heat-stroke symptoms are at the severe end (eg impending circulatory collapse, confusion), ambulance evacuation and admission are necessary.

\section{Case actions}

In answering Helen's question, we are able to say:

- We are acting through our professional organisations to mitigate future global warming.

- We will work with Helen and her mother to create a plan to manage her chronic conditions, with heat effects in mind and incorporating actions to minimise Mrs Krisolakis's future personal heat exposure.

- We will work with the pharmacist to prepare special 'hot days' Webster packs that omit the furosemide and contain only $50 \mathrm{mg}$ atenolol. The plan would remind Mrs Krisolakis to remove the oxybutynin patch.

- Within this heat-response plan, we will include a specific heat-stress action plan to detect and respond to signs of heat stress and manage her chronic diseases in heatwave settings.

\section{Key points}

- GPs need to be aware of heat stress as a potential cause of morbidity and mortality.

- The GP's role crosses the three preventive levels of mitigating GHG emissions (primordial), recognising 
vulnerable people in their practices, and working with these patients and their relatives where appropriate to plan primary and secondary prevention strategies.

\section{Authors}

Peter W Tait MBBS, DipRACOG, FRACGP, MClimChng, FPHAA, Convener Ecology and Environment Special Interest Group, Public Health Association Australia; Senior Lecturer (Clinical), ANU Medical School, ACT. aspetert@bigpond.com Sujata Allan MBBS, DCH, general practice registrar, Blacktown, NSW; Member, Doctors for the Environment Australia

Anthea L Katelaris BMed, BA, MD, MSc(Dist), Public Health Medicine registrar, Sydney; Master of Philosophy in Applied Epidemiology (MAE) scholar, National Centre for Epidemiology and Population Health, Research School of Population Health, Australian National University, ACT

Competing interests: None.

Funding: None.

Provenance and peer review: Commissioned, externally peer reviewed.

\section{References}

1. Smith KR, Woodward A. Human health: Impacts, adaptation, and co-benefits. In: Field CB, Barros VR, Dokken DJ, et al, editors. Climate change 2014: Impacts, adaptation, and vulnerability - Contribution of working group II to the Fifth Assessment Report of the Intergovernmental Panel on Climate Change. Cambridge, UK: Intergovernmental Panel on Climate Change, 2014.

2. Beaglehole R, Bonita R. Public health at the crossroads: Achievements and prospects. Cambridge, UK: Cambridge University Press, 2004.

3. Parise I. A brief review of global climate change and the public health consequences. Aust J Gen Pract 2018;47(7):451-56.

4. Hughes L, Hanna E, Fenwick J. The silent killer: Climate change and the health impacts of extreme heat. Sydney: Climate Council of Australia Ltd, 2016.

5. Guo Y, Gasparrini A, Li S, et al. Quantifying excess deaths related to heatwaves under climate change scenarios: A multicountry time series modelling study. PLoS Med 2018;15(7):e1002629. doi: 10.1371/journal.pmed.1002629.

6. Bureau of Meteorology. Heatwave service for Australia. Melbourne: BoM, 2016. Available at www.bom.gov.au/australia/heatwave/about.shtml [Accessed 8 July 2018].

7. Bureau of Meteorology, CSIRO. State of the climate 2016. Melbourne: BoM, 2016. Available at www.bom.gov.au/state-of-the-climate [Accessed 8 July 2018].

8. Coates L, Haynes K, O'Brien J, McAneney J, De Oliveira FD. Exploring 167 years of vulnerability: An examination of extreme heat events in Australia 1844-2010. Environ Sci Policy 2014;42:33-44.

9. World Meteorological Organization, World Health Organization. Heatwaves and health: Guidance on warning-system development. Geneva: WMO; WHO, 2015. Available at www.who.int/ globalchange/publications/WMO_WHO_Heat Health_Guidance_2015.pdf [Accessed 8 July 2018].
10. Department of Human Services. January 2009 heatwave in Victoria: An assessment of health impacts. Melbourne: DHS, 2012. Available at www2.health.vic.gov.au/ getfile/?sc itemid=\%7b78C32CE8-A619-47A68ED1-1C1D34566326\%7d\&title=January $\% 20$ 2009\%20Heatwave\%20in\%20Victoria\%3A\%20 an\%20Assessment\%20f\%20 Health\%20Impacts [Accessed 8 July 2018].

11. Jegasothy E, McGuire R, Nairn J, Fawcett $\mathrm{R}$, Scalley B. Extreme climatic conditions and health service utilisation across rural and metropolitan New South Wales. Int J Biometeorol 2017;61(8):1359-70. doi: 10.1007/s00484-017-1313-5.

12. Tong S, Ren $C$, Becker N. Excess deaths during the 2004 heatwave in Brisbane, Australia. Int J Biometeorol 2010;54(4):393-400. doi: 10.1007/ s00484-009-0290-8.

13. Hanna EG, Tait PW. Limitations to thermoregulation and acclimatization challenge human adaptation to global warming. Int J Environ Res Public Health 2015;12(7):8034-74. doi: 10.3390/ijerph120708034.

14. Bonita R, Beaglehole R, Kjellström T. Basic epidemiology. 2nd edn. Geneva: World Health Organization, 2006.

15. Climate and Health Alliance. National consultation regarding a national strategy on climate, health and well-being for Australia: Final consultation report. Melbourne: Climate and Health Alliance, 2017. Available at https://d3n8a8pro7vhmx. cloudfront.net/caha/pages/40/attachments/ original/1496970197/CAHA_Final_Consultation_ Report_May_2017_FINAL.pdf?14969670197 [Accessed 9 October 2018]

16. NSW Government. Clean air for NSW: Consultation paper. Sydney: Environment Protection Authority, Office of Environment and Heritage, 2016. Available at www.epa. nsw.gov.au/ /media/EPA/Corporate\%20 Site/resources/air/clean-air-nsw-160415.ashx [Accessed 8 July 2018].

17. Brown J, Bowman C. Integrated science assessment (ISA) for ozone and related photochemical oxidants. Washington, DC: US Environmental Protection Agency, 2013. Available at www.epa.gov/isa/ integrated-science-assessment-isa-ozoneand-related-photochemical-oxidants [Accessed 8 July 2018].

18. Australian Broadcasting Commission. Sydney's air pollution prompts NSW Health to issue a warning about toxic ozone gas. Sydney: ABC News, 2017. Available at www.abc.net.au/news/2017-01-10/ sydney-high-air-pollution-prompts-warning-fromnsw-heath/8171618 [Accessed 8 July 2018].

19. Straif K, Cohen A, Samet J, editors. Air pollution and cancer. IARC scientific publication no 161. Lyon, France: International Agency for Research on Cancer, 2013.

20. Brunekreef B, Holgate ST. Air pollution and health. Lancet 2002;360(9341):1233-42. doi: 10.1016/ S0140-6736(02)11274-8.

21. Cohen D, Crawford J, Stelcer E, Atanacio AJ. Revealing the sources of Sydney's air pollution. Sydney: ANSTO, 2014. Available at www. ansto.gov.au/news/revealing-sources-ofsydney\%E2\%80\%99s-air-pollution [Accessed 8 July 2018].

22. Broome RA, Fann N, Cristina TJN, Fulcher C Duc $H$, Morgan GG. The health benefits of reducing air pollution in Sydney, Australia. Environ Res 2015;143(Pt A):19-25. doi: 10.1016/j. envres.2015.09.007.
23. NSW Government. Urban green cover in NSW: Technical guidelines. Sydney: Office of Environment and Heritage, 2015. Available at https://climatechange.environment.nsw.gov. au/Adapting-to-climate-change/Green-Cover [Accessed 8 July 2018].

24. Western Sydney Regional Organisation of Councils. Turn Down the Heat. Sydney: WSROC, 2015. Available at https://wsroc. com.au/projects/project-turn-down-the-heat [Accessed 9 October 2018].

25. Mellick Lopes A, Gibson K, Crabtree L, Armstrong $\mathrm{H}$. Cooling the commons: Pilot research report. Sydney: University of Western Sydney, 2016. Available at www.westernsydney. edu.au/_data/assets/pdf_file/0020/1161470/ cooling-the-commons-report.pdf [Accessed 9 October 2018].

26. Gagnon D, Crandall CG. Electric fan use during heat waves: Turn off for the elderly? Temperature (Austin) 2017;4(2):104-06. doi: 10.1080/23328940.2017.1295833.

27. Tait PW. Medicine use, heat and thermoregulation in Australian patients. Med J Aust 2011;195(6):327.

28. Tait PW, Hanna EG. A conceptual framework for planning systemic human adaptation to global warming. Int J Environ Res Public Health 2015;12(9):10700-22. doi: 10.3390/ ijerph120910700. 